\title{
UPTAKE, ELIMINATION, AND BIOTRANSFORMATION OF AQUEOUS AND DIETARY DDT IN MARINE FISH
}

\author{
Raymond W.M. Kwong, $\dagger$ Peter K.N. Yu, $\ddagger$ Paul K.S. Lam, $\S$ and Wen-Xiong Wang*† \\ $\dagger$ Department of Biology, Hong Kong University of Science and Technology, Clear Water Bay, Kowloon, Hong Kong, China \\ ‡Department of Physics and Materials Science, §Department of Biology and Chemistry, \\ City University of Hong Kong, Tat Chee Avenue, Kowloon, Hong Kong, China
}

(Received 26 November 2007; Accepted 3 March 2008)

\begin{abstract}
To understand the biokinetics and potential risks of $p, p^{\prime}$-dichlorodiphenyltrichloroethane (DDT) and its metabolites, $p, p^{\prime}$-dichlorodiphenyldichloroethylene (DDE) and $p, p^{\prime}$-dichlorodiphenyldichloroethane (DDD), in fish, we exposed the black sea breams (Acanthopagrus schlegeli) to aqueous and dietary DDTs and then evaluated the bioaccumulation, distribution, biotransformation, and elimination of DDTs under controlled laboratory conditions. The fish rapidly accumulated DDTs from both routes of exposure, particularly the gills and viscera. Elimination of DDTs following aqueous or dietary uptake was slow, and biotranslocation of DDTs was significant during the exposure period but negligible during the depuration period. The biotransformation process was more significant following dietary exposure. During depuration, DDE was the major biotransformed product in the sea breams' carcasses while DDD was the major product in the gills and viscera. However, DDD had a significantly higher elimination rate than DDE and, subsequently, the fish retained more DDE in the body. Intraspecies variability in the elimination and biotransformation processes in fish was observed. We demonstrated that the route of exposure significantly affected the fate and biokinetics of DDTs in fish. The application of a dynamic model provided a tool for quantifying the elimination and biotransformation of DDT in fish. The present study provided insights into the bioaccumulation and biotransformation pathways of DDT in fish that could have important ecotoxicological implications.
\end{abstract}

Keywords-DDT Fish Bioaccumulation Depuration Biotransformation

\section{INTRODUCTION}

Although the use of $p, p^{\prime}$-dichlorodiphenyltrichloroethane (DDT) has been officially prohibited in many countries, DDT contamination is still a global concern due to the high persistence of DDT in the environment. DDT and its metabolites, $p, p^{\prime}$-dichlorodiphenyldichloroethylene (DDE) and $p, p^{\prime}$-dichlorodiphenyldichloroethane (DDD), are widespread in the environment and even detectable in some remote areas, such as the Arctic Ocean and deep-sea environments [1,2]. China banned the production of technical DDT in 1983, but there has been no apparent trend of decreasing concentrations of DDT in the coastal environment of south China [3]. In addition to illegal use, DDT is still used for malaria control in China and in dicofol [4] and antifouling paints. Recent inputs of DDT have been recorded in many coastal areas in Asian countries, including China, Cambodia, India, Indonesia, and Vietnam [5]. Contamination of freshwater and marine fish by DDT has been found in many countries and regions, and the low ratio of DDE to DDT in the fish suggests that new DDT is still a problem in Southeast Asia [6], where contaminated farmed seawater fish is of particular concern [7]. Thus, DDT is expected to remain a continual threat to wild and aquaculture fish, thereby raising the issue of the safety of fish consumption given that aquaculture and fishery products are the popular diets for many Asians. According to Food and Agriculture Organization of the United Nations [8; ftp.fao.org/fi/stat/overview/2001/ commodit/2001fisheryoverview.pdf], more than $80 \%$ of the global aquaculture production originates in Asia.

Bioaccumulation of DDT in fish [6,7] and its biomagnifi-

\footnotetext{
* To whom correspondence may be addressed (wwang@ust.hk).
} Published on the Web 4/2/2008. cations along the aquatic food chain have been well documented $[9,10]$. Not only does DDT adversely affect the health status of fish, but it also poses a serious threat to human health [11]. Fish are known to metabolize DDT [12], but the biological fate of DDT in fish is poorly understood because of the many complex biological processes that occur simultaneously in fish, such as the differential bioaccumulation and elimination of various DDT metabolites, biotranslocation of DDT among organs, and biotransformation of DDT. Partitioning and uptake kinetics of hydrophobic pollutants in fish may be characterized using the octanol-water partition coefficient or the bioconcentration factor [13,14]; however, these models have shown inaccuracy in quantifying the biokinetics and the biological fate of the compounds that undergo substantial biotransformation processes in the animals $[15,16]$. In addition, toxicity generally occurs in tissues or organs that contain relatively small amounts of lipid (e.g., liver vs visceral fats) [13] and alteration in the form of the toxicant within the animals after exposure could have important toxicological implications because the biokinetics, mode of action, and toxicity of the metabolites could be very different from the parent compound [17-19]. For example, it is known that DDT and DDD act as xenobiotic estrogens but DDE is an antiandrogen. Therefore, to evaluate the potential risks of DDT and its metabolites, improving knowledge for the biotransformation pathway and the biokinetics of DDT in fish is important.

Recently, dynamic models have been employed to evaluate the biokinetics of toxic compounds that are susceptible to biotransformation, such as the paralytic shellfish toxins [19]. These modeling efforts may provide vital information on the future development of predictive ecological risk assessment models and give insight into the biotransformation pathway 
of toxic compounds within the animals. In the present study, we quantified the bioaccumulation, distribution, and elimination of DDT and its metabolites (DDD and DDE) in a marine fish. We compared the biokinetics of aqueous and dietary sources of DDTs in the fish. The marine black sea bream (Acanthopagrus schlegeli) was used as a model organism due to its economic importance in Asia. Following these experimental measurements, we then employed a dynamic model to evaluate the biokinetics of DDT in marine fish through aqueous and dietary exposure. To our knowledge, this is the first study to model the biotransformation of DDTs in aquatic organisms.

\section{MATERIALS AND METHODS}

Organisms, chemicals, and food preparation

The A. schlegeli $(5.3 \pm 1.5 \mathrm{~g}$ wet wt, $n=54)$ fish were obtained from a fish farm at Yung Shue O, Sai Kung, Hong Kong. After being brought to the laboratory, the fish were maintained in a flow-through system receiving natural coastal seawater collected from Clear Water Bay, Hong Kong, at $23^{\circ} \mathrm{C}$ and 30 practical salinity units, with continuous aeration. They were acclimated to laboratory conditions for $7 \mathrm{~d}$ and fed commercial shrimp during the acclimation and depuration periods at a ration of $2 \%$ wet wt.

The DDT was obtained from Sigma-Aldrich (St. Louis, MO, USA; product 386340). After serial dilution with acetone (high-performance liquid chromatography grade), DDT was stored at $4^{\circ} \mathrm{C}$ in the dark before use. For the dietary uptake experiment, the food (commercial shrimp) was spiked with 10 $\mu \mathrm{g} / \mathrm{L}$ of DDT $(6 \mu \mathrm{g}$ in $600 \mathrm{ml}$ of $0.2-\mu \mathrm{m}$ filtered seawater) for $24 \mathrm{~h}$ in the dark at $4^{\circ} \mathrm{C}$ with continuous shaking, and the solvent was gently dried prior to feeding to the fish. The food was subsequently analyzed for DDT and its metabolites (DDD and DDE).

\section{Uptake and depuration of aqueous DDT in fish}

Thirty-five fish were placed in a fish tank containing 200 $\mathrm{L}$ of seawater and receiving continuous aeration. Each day, the fish were fed commercial shrimp prior to exposure, and the excess shrimp were removed $2 \mathrm{~h}$ after feeding. The fish were first exposed to $500 \mathrm{ng} / \mathrm{L}$ of DDT, and the concentration of DDT was maintained by continuous refreshing from a stock solution at a rate of $250 \mathrm{ng} / \mathrm{L} / \mathrm{h}$ using a peristaltic pump. The solvent to seawater ratio was less than $0.0002 \%$. The fish were exposed for $7 \mathrm{~d}$, followed by two weeks of depuration in a flow-through system. Feces were removed by a siphon tube daily, and half of the seawater was renewed during the uptake period. Three fish were sampled randomly $(n=3)$ on days 1 , $2,3,5$, and 7 during exposure and on days $1,3,5$, and 14 during the depuration period. The fish were dissected into gills, viscera (gastrointestinal tract and internal organs), and carcasses (head, muscular tissue, fins, skin, and bone); weighed; and then stored at $-80^{\circ} \mathrm{C}$ immediately after dissection.

\section{Uptake and depuration of dietary DDT in fish}

Thirty-five fish were placed in a fish tank containing 200 L of seawater receiving continuous aeration. The DDT-spiked food was fed to the fish twice a day at a ration of $2 \%$ wet wt, and any unconsumed food was removed afterward. Water quality was monitored before and after feeding, and the aqueous DDT level was below the detection limit. The fish were exposed to spiked food for $7 \mathrm{~d}$ in the static system, followed by two weeks of depuration in the flow-through system. The food was replaced by nonspiked commercial shrimp during the dep- uration period. Half of the seawater was renewed daily, and feces were removed by a siphon tube. Three fish were sampled randomly $(n=3)$ on days $1,2,3,5$, and 7 during exposure and on days $3,5,7$, and 14 during the depuration period. Similarly, the fish were dissected into gills, viscera, and carcasses; weighed; and then stored at $-80^{\circ} \mathrm{C}$ immediately after dissection.

\section{Tissue extraction, sample cleanup, and chemical analysis}

Fish tissues were freeze-dried before being ground into powder, and a known amount of tissue powder was weighed into a 50-ml centrifuge tube. Anhydrous sodium sulfate and $15 \mathrm{ml}$ of methylene chloride were added and shaken for 30 min using a horizontal shaker. The mixture was then centrifuged at 2,000 rpm for $10 \mathrm{~min}$. The supernatant was collected, and the sample was extracted two more times with $15 \mathrm{ml}$ of methylene chloride. All the supernatants were combined and filtered by means of glass fiber filters, and the remaining extract was concentrated to approximately $5 \mathrm{ml}$ using a rotary evaporator. The solvent was exchanged by adding $20 \mathrm{ml}$ of hexane, then the volume was reduced to $1 \mathrm{ml}$. The lipid content was determined from an aliquot of the extract by reducing to dryness using gentle air blowdown.

Sample cleanup was similar to the methods described in U.S. Environmental Protection Agency method 3620c [20]. Briefly, the Florisil ${ }^{\circledR}$ cartridge (Waters, Milford, MA, USA) was first preconditioned with hexane, followed by the addition of the samples, and was then eluted with acetone:hexane (10: $90, \mathrm{v} / \mathrm{v})$. All reagents used were of analytical or high-performance liquid chromatography grade.

The identification and quantification of DDT, DDD, and DDE, and the procedure for quality assurance and quality control, were similar to the methods described by Cornish et al. [21] but had some modifications. The analysis of DDT, DDD, and DDE was carried out by a Hewlett-Packard 6890 series gas chromatograph equipped with both a microelectron capture detector installed with a DB-5MS capillary column $(60 \mathrm{~m}$ length, $0.25 \mathrm{~mm}$ inner diameter, $0.25-\mu \mathrm{m}$ film thickness; J\&W Scientific, Folsom, CA, USA) and an auto injector and sampler (Hewlett-Packard 7683 series). The oven temperature was programmed from $80^{\circ} \mathrm{C}$ at the beginning, held for $1 \mathrm{~min}$, then increased to $210^{\circ} \mathrm{C}$ at a rate of $10^{\circ} \mathrm{C} / \mathrm{min}$; after that, it was increased to $250^{\circ} \mathrm{C}$ at a rate of $0.8^{\circ} \mathrm{C} / \mathrm{min}$ and finally raised to $290^{\circ} \mathrm{C}$ at a rate of $10^{\circ} \mathrm{C} / \mathrm{min}$ and held for $10 \mathrm{~min}$. Injector and detector temperatures were set at 250 and $290^{\circ} \mathrm{C}$, respectively. Procedural blanks were included to check for potential contamination. Standard reference material (SRM-2978; National Institute of Standards and Technology, Gaithersburg, MD, USA) was used to test the recovery of DDTs. Percentage recovery was over $80 \%$, and no correction of data was made for the recovery.

\section{Statistical analysis}

One-way analysis of variance was used to test for differences in the accumulation of DDTs among organs (gills, viscera, and carcass), followed by a least significant difference test to identify the differences among groups. All statistical tests were performed using SPSS ${ }^{\circledR}$ for Windows ${ }^{\circledR}$ (ver 10; Chicago, IL, USA). Data were reported as means \pm standard deviation, and statistical difference was accepted at $p<0.05$.

\section{Model development}

The general mathematical model employed in the present work was a two-level compartmental model, meaning that 
a)

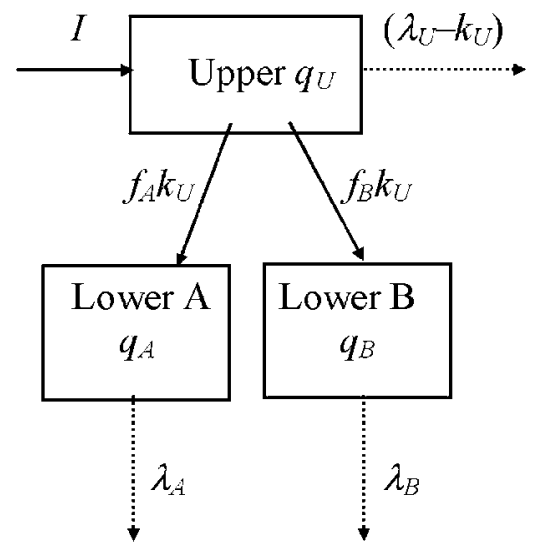

b)

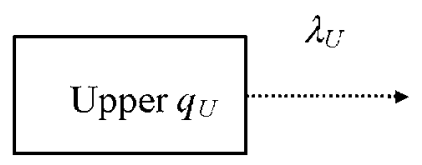

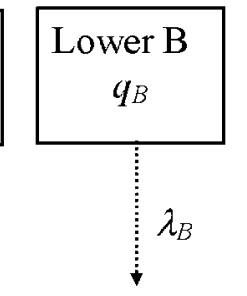

c)

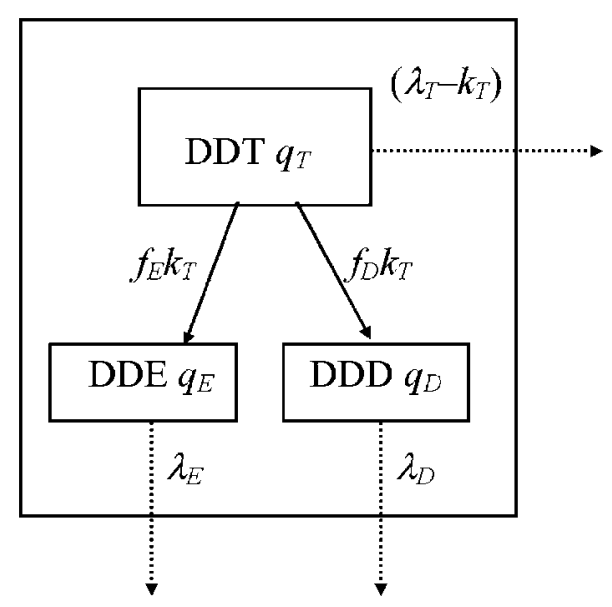

Fig. 1. The compartment model applied in the present study. (a) a general two-level compartment model; (b) a compartment model with the neglected biotranslocation $\left(k_{U}=0\right)$; (c) a two-level subcompartment model for biotransformation from DDT to $p, p^{\prime}$-dichlorodiphenyldichloroethylene (DDE) and $p, p^{\prime}$-dichlorodiphenyldichloroethane (DDD) in the viscera, gills, or carcass compartment for the case of dietary uptake. The explanations of each parameter are shown in Table 1.

DDT from aqueous and dietary uptake was first input into the first-level (or upper-level) compartment, and DDT in the firstlevel compartment was then transferred to the second-level compartment. Regarding clearance, DDT from the first-level compartment could be either eliminated directly from the compartment (e.g., excretion) or transferred to the second-level

Table 1. Parameters used in the compartment scheme shown in Figure $1^{\mathrm{a}}$

\begin{tabular}{|c|c|c|}
\hline Parameter & Description & Unit \\
\hline$I$ & $\begin{array}{l}\text { Nanograms of DDT into the upper compart- } \\
\text { ment per day }\end{array}$ & $\mathrm{ng} / \mathrm{d}$ \\
\hline$f_{A} k_{U}$ & Transfer coefficient from upper to lower $A$ & $d^{-1}$ \\
\hline$f_{B} k_{U}$ & Transfer coefficient from upper to lower $B$ & $\mathrm{~d}^{-1}$ \\
\hline$q_{i}$ & $\begin{array}{l}\text { Nanograms per gram of toxin in the } i \text { th com- } \\
\text { partment }\end{array}$ & $\mathrm{ng} / \mathrm{g}$ \\
\hline$m_{i}$ & Dry mass of the $i$ th compartment & $\mathrm{g}$ \\
\hline$\lambda_{i}$ & Removal rate from the $i$ th compartment & $\mathrm{d}^{-1}$ \\
\hline
\end{tabular}

a $i=U, A$, and $B$ stands for the upper, lower $A$, and lower $B$ compartments, respectively.

compartment (e.g., biotranslocation). From the second-level compartment, DDT was solely eliminated from the compartment into the surrounding environment. In the present study, a two-level compartmental model with a single upper level (denoted as $U$ ) and two lower levels (denoted as $A$ and $B$ ) was applied. The general compartmental scheme is shown in Figure $1 \mathrm{a}$, with the parameters explained in Table 1. The measured dry and lipid masses of different compartments of A. schlegeli in the aqueous and dietary uptake experiments are shown in Table 2.

Because the uptake of DDT was linear in both aqueous and dietary uptake, the mathematical models developed in the present study focused primarily on the depuration phase, i.e., $I=$ 0 . The differential equation governing the depuration for the upper compartment is:

$$
\frac{d q_{U}}{d t}=-\lambda_{U} q_{U}
$$

The differential equation governing the depuration for the lower compartments is $(j=A, B)$ :

$$
\frac{d q_{j}}{d t}=\frac{m_{U}}{m_{j}} f_{j} k_{U} q_{U}-\lambda_{j} q_{j}
$$

The time-dependent DDT concentrations in each of the three compartments during depuration with the initial conditions (on day 7$), q_{U}(0)=q_{U_{0}}$ and $q_{j}(0)=q_{j 0}$, are, respectively:

$$
\begin{aligned}
q_{U} & =q_{U_{0}} e^{-\lambda_{U} t} \\
q_{j} & =q_{j_{0}} e^{-\lambda_{j} t}+\frac{m_{U}}{m_{j}} f_{j} k_{U} q_{U_{0}} e^{-\lambda_{U} t}\left(\frac{e^{-\lambda_{U} t}-e^{-\lambda_{j} t}}{\lambda_{j}-\lambda_{U}}\right)
\end{aligned}
$$

The general two-level compartmental model was employed for both aqueous and dietary uptake. Aqueous DDT was mainly taken up by the gills and then transported to other parts of the body by means of blood [22,23]; therefore, for the develop-

Table 2. Measured dry mass and lipid mass of different compartments of Acanthopagrus schlegeli in the experiments for aqueous and dietary uptake

\begin{tabular}{lclc}
\hline Experiment & Gills & Viscera & Carcass \\
\hline Aqueous uptake & & & \\
Dry mass (g) & $0.04 \pm 0.01$ & $0.13 \pm 0.05$ & $1.37 \pm 0.40$ \\
Lipid mass (mg) & $0.88 \pm 0.39$ & $2.29 \pm 0.9$ & $8.73 \pm 3.98$ \\
Dietary uptake & & & \\
Dry mass (g) & $0.04 \pm 0.01$ & $0.11 \pm 0.04$ & $1.26 \pm 0.27$ \\
Lipid mass (mg) & $0.72 \pm 0.44$ & $2.28 \pm 0.99$ & $8.70 \pm 2.18$ \\
\hline
\end{tabular}

a Mean \pm standard deviation $(n=10)$. 
ment of the aqueous uptake model, we took the gills $(G)$ as the upper compartment and the viscera $(V)$ and the carcass $(T)$ as the two lower compartments. On the other hand, for the dietary uptake model, the viscera were taken as the upper compartment and the gills and the carcass as the two lower compartments.

In both the aqueous and the dietary uptake experiments, the complete model was complicated because DDT could be biotransformed and biotranslocated among various compartments, or vice versa. Based on our results (discussed later), biotranslocation of DDT among organs is not significant during the depuration period (i.e., $k_{U}=0$ ). Therefore, we assumed that the biotranslocation processes were negligible during depuration. A modified compartmental model was then subsequently employed (Fig. 1b). Effectively, for modeling with no biotranslocation in the depuration phase, all compartments could be treated as the first-level (or upper-level) compartments since there were no transfers among different compartments. As a result, Equations 1 and 3 were used.

For the dietary uptake, we also attempted to model the biotransformation processes due to the higher DDT metabolites observed during depuration period (see Results section). Under our assumption of negligible translocation among organs during depuration period, DDT, DDD, and DDE were only transformed among themselves within the same compartment, and the biotransformation processes occurred in each compartment independently. In addition, based on the biotransformation pathway of DDT in fish (DDT converts to DDE or to DDD [24]), we could employ the two-level compartmental model as shown in Figure 1a to model the processes of biotransformation in each organ. Each DDT compound (DDT, DDE, and DDD) was treated as a subcompartment within each organ compartment (viscera, gills, and carcass), with DDT as the upper subcompartment and DDE and DDD as the lower subcompartments. The compartmental scheme for the biotransformation processes is illustrated in Figure 1c, and Equations 1 to 4 were used for the calculations. In the following, the term "biotranslocation" will refer to the transfer/distribution of DDT among organs, while the term "biotransformation" will refer to the conversion from DDT to DDE or to DDD.

\section{RESULTS}

\section{Composition of DDTs and growth of fish}

Total aqueous DDTs contained mostly DDT (65.7\%), with $32.7 \%$ DDD and only a trace amount of DDE (1.6\%). In the food, DDT was also predominant, accounting for $72.4 \%$, while DDD and DDE accounted for 9.0 and $18.5 \%$, respectively. No significant differences of dry and lipid masses of the fish between day 1 and day $21(p>0.05)$ were found, suggesting neither positive nor negative growth in the three-week experimental period.

\section{Accumulation and depuration of aqueous DDTs in fish}

The concentrations of total DDTs (DDT, DDD, and DDE) in the gills, viscera, and carcasses increased linearly with the exposure time (Fig. 2a). On the last day of exposure (day 7), DDTs in the gills and viscera were significantly greater than those in the carcasses $(p<0.01)$, whereas no statistically significant differences between the gills and the viscera $(p>$ $0.1)$ were observed. The highest accumulation of DDTs followed the order of viscera $>$ gills $>$ carcasses. In the gills,
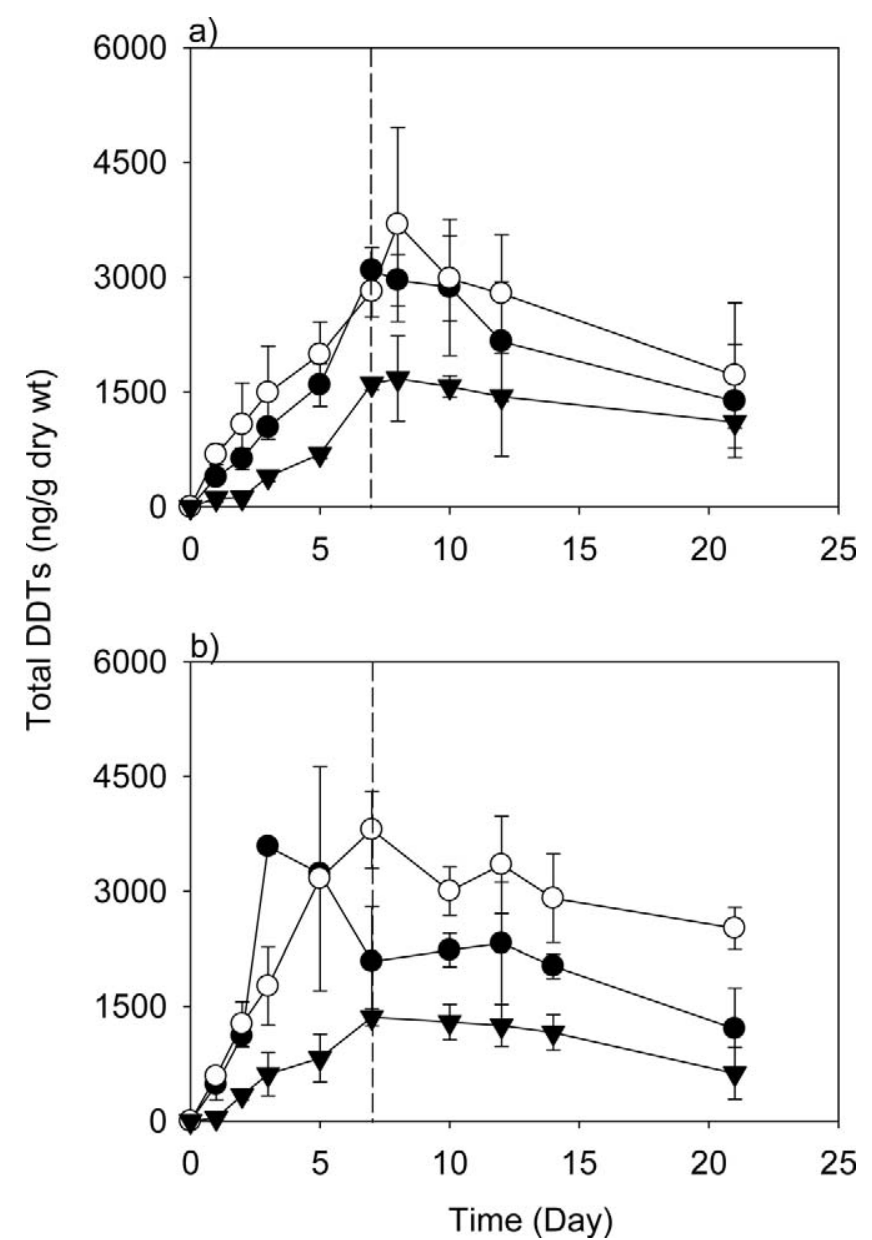

Fig. 2. Changes in total DDTs (summation of DDT, $p, p^{\prime}$-dichlorodiphenyldichloroethane, and $p, p^{\prime}$-dichlorodiphenyldichloroethylene) of different compartments in the fish Acanthopagrus schlegeli through (a) aqueous DDT uptake and (b) dietary DDT uptake during the whole experimental period (day 1-7 exposure, day 8-21 depuration). Mean \pm standard deviation $(n=3)$. $-\longrightarrow-=$ gills; $-\bigcirc-=$ viscera; $-\boldsymbol{\nabla}-=$ carcass.

total DDTs reached the highest concentration of 3,088 \pm 302 $\mathrm{ng} / \mathrm{g}$ dry wt on day 7, whereas in the viscera and the carcasses, total DDTs reached the highest concentration of 3,686 $\pm 1,270$ and $1,676 \pm 555 \mathrm{ng} / \mathrm{g}$, respectively, on the first day of depuration (day 8). Over the two-week depuration period, 55.2\% of DDTs was eliminated from the gills, while only 38.9 and $31.2 \%$ of DDTs were eliminated from the viscera and the carcasses, respectively. Overall, $44 \%$ of the total DDTs was eliminated from the whole body after two weeks of depuration.

The DDT metabolites increased with exposure time during the uptake period, but the accumulation of DDT was markedly higher than that of DDD and DDE in all organs over the course of the experiment (Fig. 3). Comparing the composition of DDTs in the water phase to that in the fish, DDT was markedly more pronounced in fish despite the considerable amount of DDD present in the dosage. Thus, both higher water concentration and higher uptake of DDT than DDD accounted for the levels in fish. The highest concentration of DDT was achieved on day 7 in all organs $(2,765 \pm 267,2,201 \pm 285$, and $1,375 \pm 60 \mathrm{ng} / \mathrm{g}$ in the gills, viscera, and carcasses, respectively). During depuration, 54.3 and $42.9 \%$ of DDT were lost from the gills and carcasses, respectively, whereas only $34.2 \%$ of DDT was removed from the viscera. 

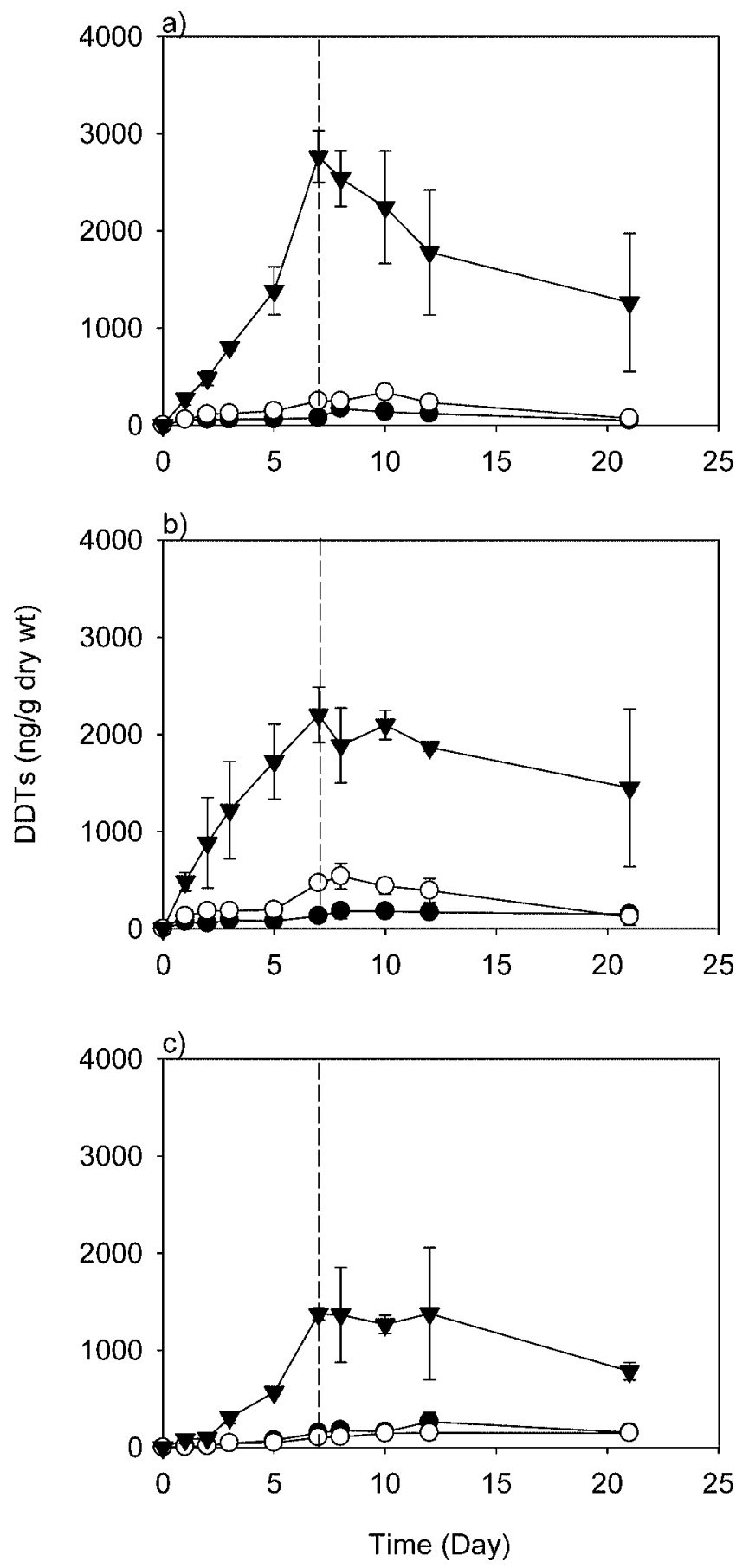

Fig. 3. Changes in concentrations of DDT $(\boldsymbol{\nabla}), p, p^{\prime}$-dichlorodiphenyldichloroethane (DDD; $\bigcirc$ ), and $p, p^{\prime}$-dichlorodiphenyldichloroethylene (DDE; ) in the (a) gills, (b) viscera, and (c) carcass of the fish Acanthopagrus schlegeli exposed to aqueous DDT during the whole experimental period (day 1-7 exposure, day 8-21 depuration). Mean \pm standard deviation $(n=3)$.

The majority of total DDTs was confined to the viscera during the aqueous uptake period (Fig. 4), accounting for $50.7 \%$ on average; $36.0 \%$ of DDTs was in the gills, and only $13.4 \%$ was observed in the carcasses. The proportion of total DDTs decreased in the viscera while it increased in the carcasses with increasing exposure time; however, the distribution of DDTs among organs was steady over the depuration period; $38.5,36.6$, and $24.9 \%$ of DDTs were distributed in the viscera, gills, and carcasses, respectively, over the depuration period.

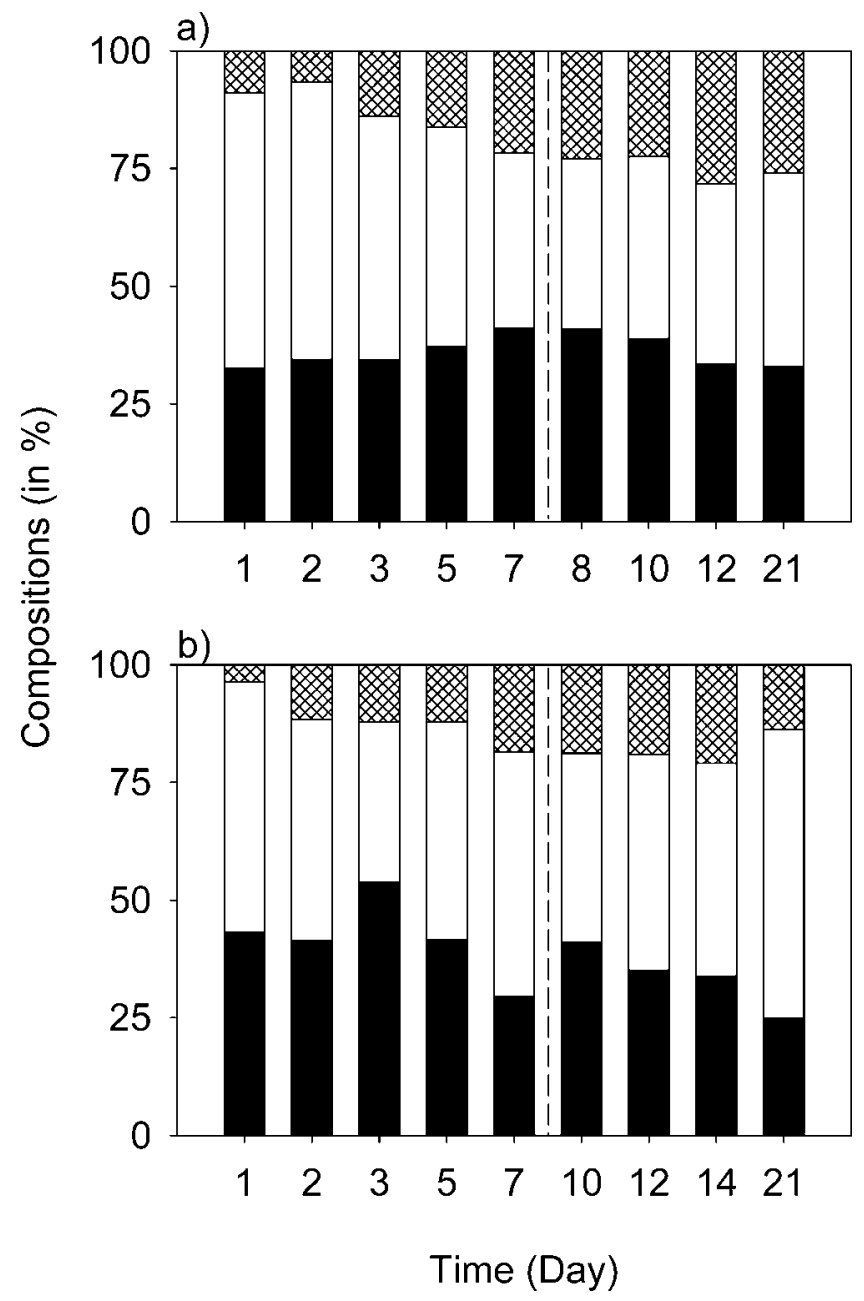

Fig. 4. Anatomical distribution of total DDTs (summation of DDT, $p, p^{\prime}$-dichlorodiphenyldichloroethane, and $p, p^{\prime}$-dichlorodiphenyldichloroethylene) through (a) aqueous DDT uptake and (b) dietary DDT uptake during the whole experimental period (day 1-7 exposure, day 8-21 depuration). $\square=$ gills; $\square=$ viscera; $\otimes=$ carcass.

\section{Accumulation and depuration of dietary DDTs in fish}

The DDTs increased linearly with the exposure time and reached the highest concentrations on the last day of exposure (day 7; Fig. 2b)—except in the gills, where the highest DDTs concentration was recorded on the third day of exposure. On day 7, concentrations of DDTs in the gills, viscera, and carcasses were 2,083 $\pm 716,3,803 \pm 500$, and 1,359 \pm 113 $\mathrm{ng} / \mathrm{g}$, respectively. The order of accumulation upon dietary exposure is similar to that following aqueous uptake (viscera $>$ gills $>$ carcasses). In addition, the concentration of DDTs in the viscera was significantly greater than in the gills and the carcasses on day $7(p<0.01)$, whereas no statistically significant difference between the gills and the carcasses $(p$ $>0.1$ ) was found. The total DDTs decreased gradually during the subsequent depuration period. Elimination of DDT from the viscera was the slowest; only $33.8 \%$ was lost over two weeks of depuration. In contrast, the removal of DDTs from the gills and the carcasses was 42.0 and $54.2 \%$, respectively. Overall, only $38 \%$ of the total DDTs was eliminated from the whole body after two weeks of depuration.

The most dominant compound in all organs was DDT, and it increased over the exposure period, followed by a decrease during the depuration period (Fig. 5). On day 7, DDT reached 

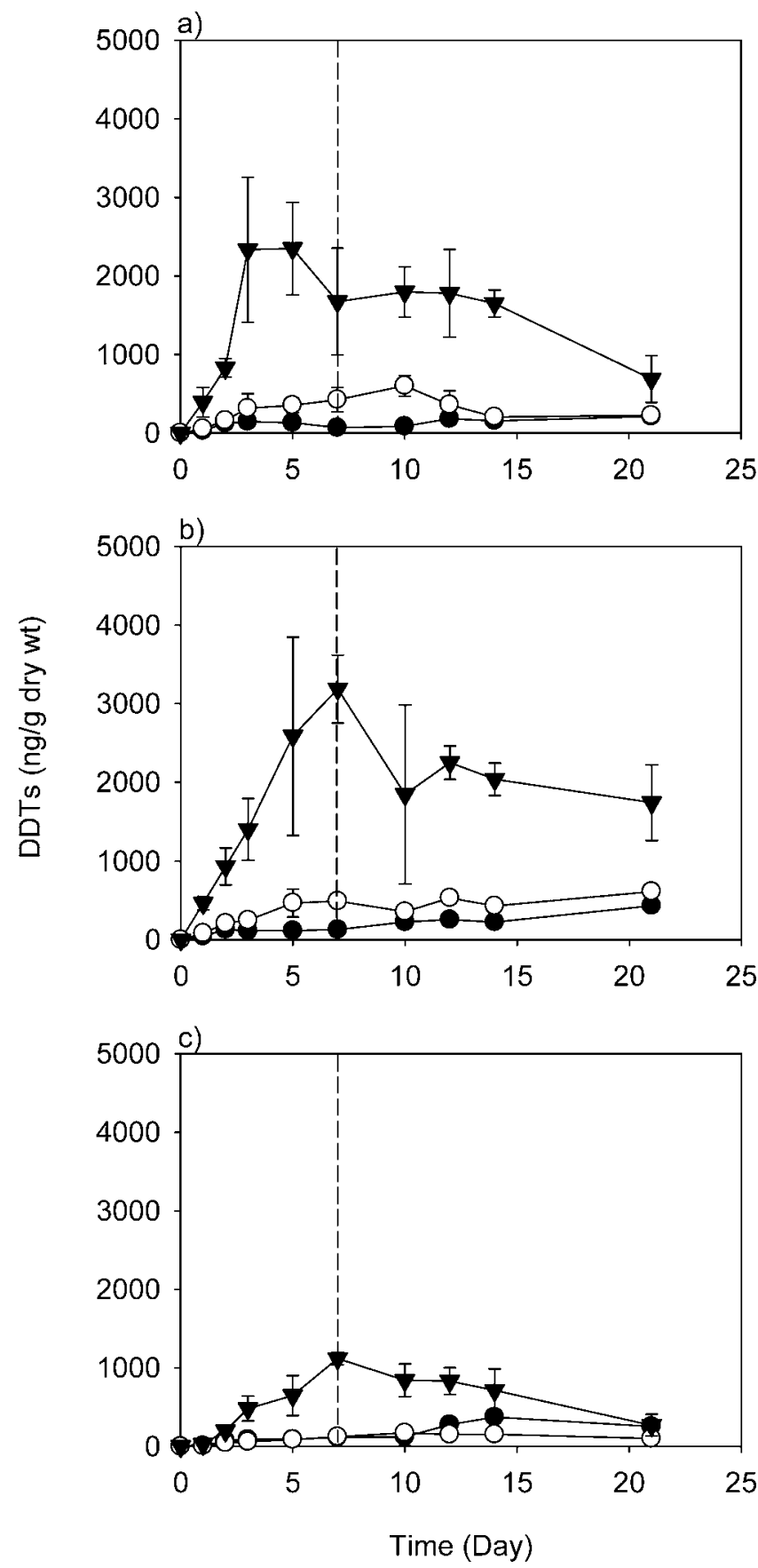

Fig. 5. Changes in concentrations of DDT $(\boldsymbol{\nabla}), p, p^{\prime}$-dichlorodiphenyldichloroethane $(\bigcirc)$, and $p, p^{\prime}$-dichlorodiphenyldichloroethylene $(\mathbf{O})$ in the (a) gills, (b) viscera, and (c) carcass of the fish Acanthopagrus schlegeli exposed to dietary DDT during the whole experimental period (day 1-7 exposure, day 8-21 depuration). Mean \pm standard deviation $(n=3)$.

$1,672 \pm 680,3,186 \pm 432$, and $1,119 \pm 79 \mathrm{ng} / \mathrm{g}$ in the gills, viscera, and carcass, respectively. Elimination of DDT was greater than elimination of the other metabolites (DDD and DDE). Over the depuration period, DDT loss from the gills, viscera, and carcasses was 58.9, 45.4, and $75.9 \%$, respectively. In contrast, concentrations of DDE and DDD increased gradually during the depuration period, especially in the viscera.

The majority of total DDTs was confined to the viscera during the exposure period, which accounted for $46.5 \%$ on average (Fig. 4). A considerable amount of DDTs was also allocated in the gills, accounting for $41.9 \%$, while only $11.6 \%$ of DDTs was distributed in the carcasses. The proportion of DDTs in the gills decreased, while that in the carcasses increased with increasing exposure time. Nevertheless, the proportion of DDTs in each organ was steady over the depuration period, suggesting no reallocation of DDTs among organs occurred during the depuration period. Over the depuration period, $48.2,33.7$, and $18.1 \%$ of DDTs were distributed in the viscera, gills, and the carcasses, respectively.

\section{Model fitting of aqueous uptake}

The experimental data were fitted using user-defined expressions in the nonlinear curve fit program, Microcal ${ }^{\mathbb{T i}}$ Origin $^{\text {(vid }}$ (ver 6.0; OriginLab, Northampton, MA, USA), with the parameters of interest as the user-defined parameters. Modeling the biokinetics of aqueous DDT uptake in fish involved a single compartment because the biotranslocation among compartments was negligible during the depuration period (see previous discussion); therefore, Equations 1 and 3 were used. The best-fit plots are shown in Figure 6, and the fitted parameters are summarized in Table 3 . The $q_{V}, q_{G}$, and $q_{T}$ variables represent the DDT concentrations in the viscera, gills, and carcasses, respectively, while $\lambda_{T}, \lambda_{E}$, and $\lambda_{D}$ represent the removal rates of DDT, DDE, and DDD, respectively, from each compartment.

The $q_{0}$ values obtained from the fitted model were comparable to the actual measurements. These results provided additional evidence that the maximum accumulations of DDT in the gills and viscera were significantly greater than the maximum accumulation in the carcass. The $\lambda$ values showed that the depuration of DDT in the gills was comparatively faster while the removal rates of DDT from the viscera and the carcass were similar. In addition, it is worth noting that there were significant differences between the $\lambda$ values for DDT and those for its metabolites in various compartments, suggesting differential elimination of each DDT compound. Elimination of DDE was the slowest among the DDT compounds in the viscera and carcasses; removal of DDD was comparatively faster.

\section{Model fitting of dietary uptake}

The model fitting for dietary DDT uptake was complicated because, unlike for aqueous DDT uptake, metabolites (DDD and DDE) were significantly higher after dietary exposure. Therefore, a two-level subcompartmental model was employed (as shown in Fig. 1c) and Equations 1 to 4 were used to model the biotransformation processes. The DDT subcompartment was the first-level compartment, while the DDE and DDD subcompartments were the second-level compartments. Results from the modeling efforts are shown in Figure 7, and the fitted parameters are summarized in Table 4. The $f_{E} \lambda_{T}$ and $f_{D} \lambda_{T}$ variables signify biotransformation from DDT to DDE and DDD, respectively. The $\lambda_{T}$ variable is the total removal rate from the DDT compartment. Theoretically, due to the conservation of DDT, we should have $f_{E} \lambda_{T}+f_{D} \lambda_{T} \leq \lambda_{T}$ (or $f_{E}+$ $\left.f_{D} \leq 1\right)$. This condition was fulfilled for all our studied cases, which indicates that our model is realistic and the results are reliable.

The $q_{0}$ values determined from the fitted model were comparable to the actual measurements. Interestingly, DDE in all compartments and DDD in the viscera increased over the depuration period (Fig. 7). Results obtained from the biokinetic model (Table 4) showed that $87 \%$ of DDT in the carcasses 
(a)
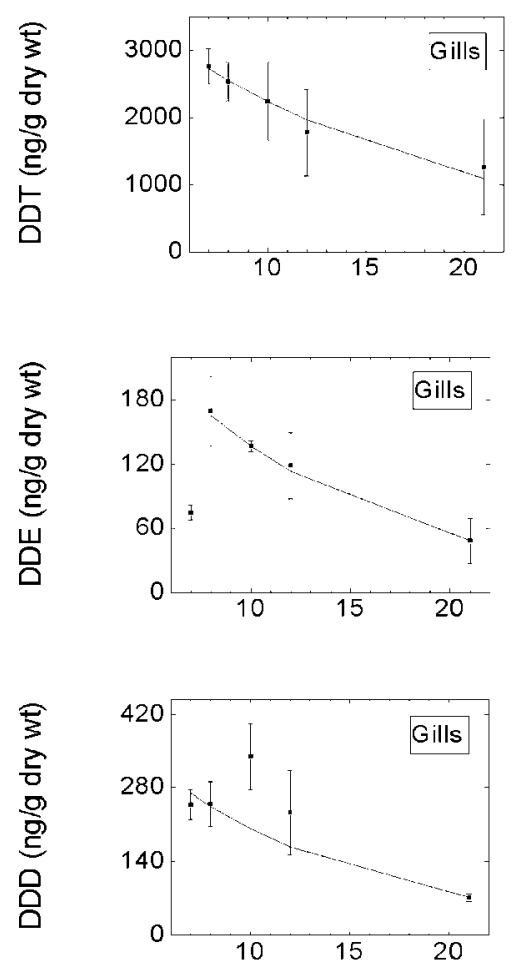

(b)
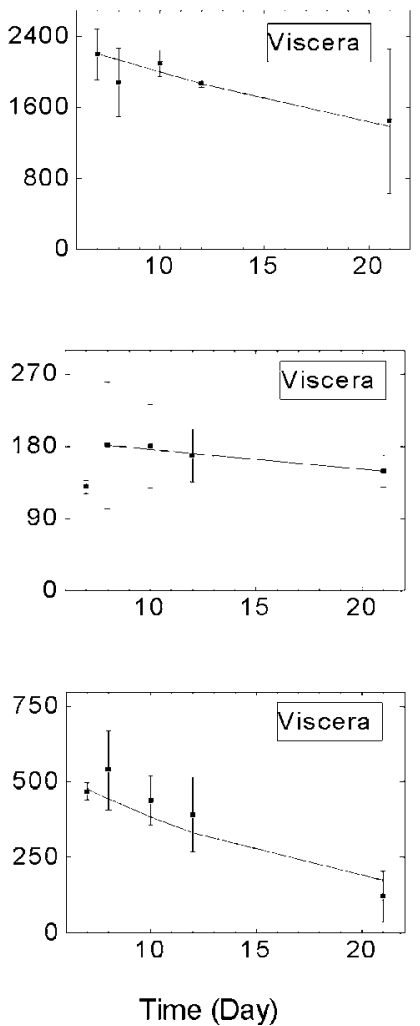
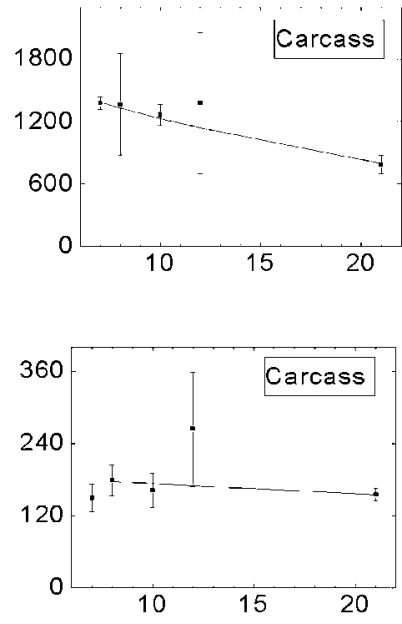

(c)

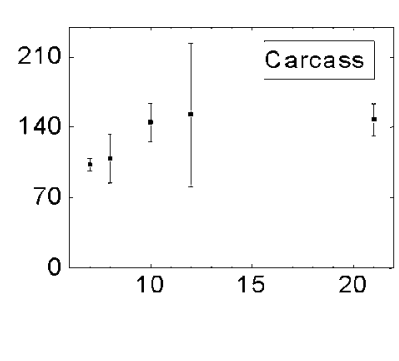

Fig. 6. Concentrations of DDT, $p, p^{\prime}$-dichlorodiphenyldichloroethylene (DDE), and $p, p^{\prime}$-dichlorodiphenyldichloroethane (DDD) in the three compartments of Acanthopagrus schlegeli-(a) gills, (b) viscera, and (c) carcass-following aqueous uptake. The line is the best fit, starting from the last day of exposure (day 7-21). Mean \pm standard deviation $(n=3)$. There is no fitting for DDD for the carcass compartment.

was biotransformed to its metabolites during depuration. The majority of DDT in the carcasses was biotransformed to DDE (79\%), whereas only $8 \%$ of DDT was biotransformed to DDD. On the other hand, 44 to $51 \%$ of DDT in the viscera and the gills was biotransformed to its metabolites during depuration, while the biotransformation from DDT to DDD was apparently higher than that from DDT to DDE in these organs (in the viscera and the gills, DDT to DDD was 35-37\%, while DDT to DDE was $8-15 \%$ ). However, DDD was characterized by significantly higher removal rates than was DDE, while negative removal rates of DDE from the viscera and gills suggested no elimination of DDE occurred over the depuration period (Table 4).

\section{DISCUSSION}

\section{Aqueous uptake}

In the present study, both routes of DDT uptake (gills and gastrointestinal tract) and differences in the biokinetics of DDTs in fish following aqueous and dietary exposure were evaluated. We observed that the aqueous DDTs were mostly DDT but also contained a comparatively high proportion of DDD. It is reported that DDT in seawater can be degraded to its metabolites photochemically and/or microbially, with DDD being the major metabolite [12]. Therefore, the elevated DDD concentration in the aqueous medium could mimic the realistic conditions in natural environment.

Table 3. Summary of the results for aqueous uptake of DDT, DDE, and DDD during depuration, including the concentrations at the end of the exposure and the removal rates from different compartments during the depuration period ${ }^{\text {ab }}$

\begin{tabular}{|c|c|c|c|}
\hline & DDT & DDE & DDD \\
\hline \multicolumn{4}{|l|}{ Viscera } \\
\hline $\begin{array}{l}q_{V_{0}}(\mathrm{ng} / \mathrm{g}) \\
\lambda_{T}, \lambda_{E}, \text { or } \lambda_{D}\left(\mathrm{~d}^{-1}\right)\end{array}$ & $\begin{array}{l}2,210 \pm 200 \\
0.033 \pm 0.019\end{array}$ & $\begin{aligned} 184 & \pm 40 \\
0.015 & \pm 0.020\end{aligned}$ & $\begin{aligned} 477 & \pm 26 \\
0.072 & \pm 0.030\end{aligned}$ \\
\hline \multicolumn{4}{|l|}{ Gills } \\
\hline $\begin{array}{l}q_{G_{0}}(\mathrm{ng} / \mathrm{g}) \\
\lambda_{T}, \lambda_{E}, \text { or } \lambda_{D}\left(\mathrm{~d}^{-1}\right)\end{array}$ & $\begin{array}{l}2,730 \pm 210 \\
0.066 \pm 0.038\end{array}$ & $\begin{aligned} 182 & \pm 21 \\
0.095 & \pm 0.036\end{aligned}$ & $\begin{aligned} 269 & \pm 24 \\
0.094 & \pm 0.010\end{aligned}$ \\
\hline \multicolumn{4}{|l|}{ Carcass } \\
\hline $\begin{array}{l}q_{T_{0}}(\mathrm{ng} / \mathrm{g}) \\
\lambda_{T}, \lambda_{E}, \text { or } \lambda_{D}\left(\mathrm{~d}^{-1}\right)\end{array}$ & $\begin{array}{l}1,390 \pm 60 \\
0.040 \pm 0.009\end{array}$ & $\begin{array}{c}178 \pm 22 \\
0.010 \pm 0.010\end{array}$ & $\begin{array}{l}\text { NA } \\
\text { NA }\end{array}$ \\
\hline
\end{tabular}

a Mean \pm standard deviation $(n=3)$.

${ }^{\mathrm{b}} \mathrm{DDD}=p, p^{\prime}$-dichlorodiphenyldichloroethane; $\mathrm{DDE}=p, p^{\prime}$-dichlorodiphenyldichloroethylene; NA $=$ values could not be found using the current model. 
(a)
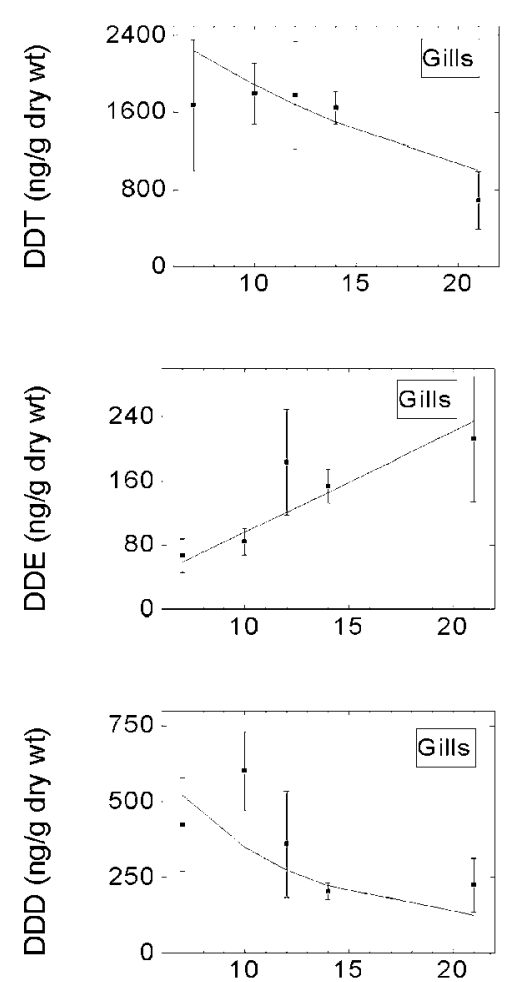

(b)

(c)
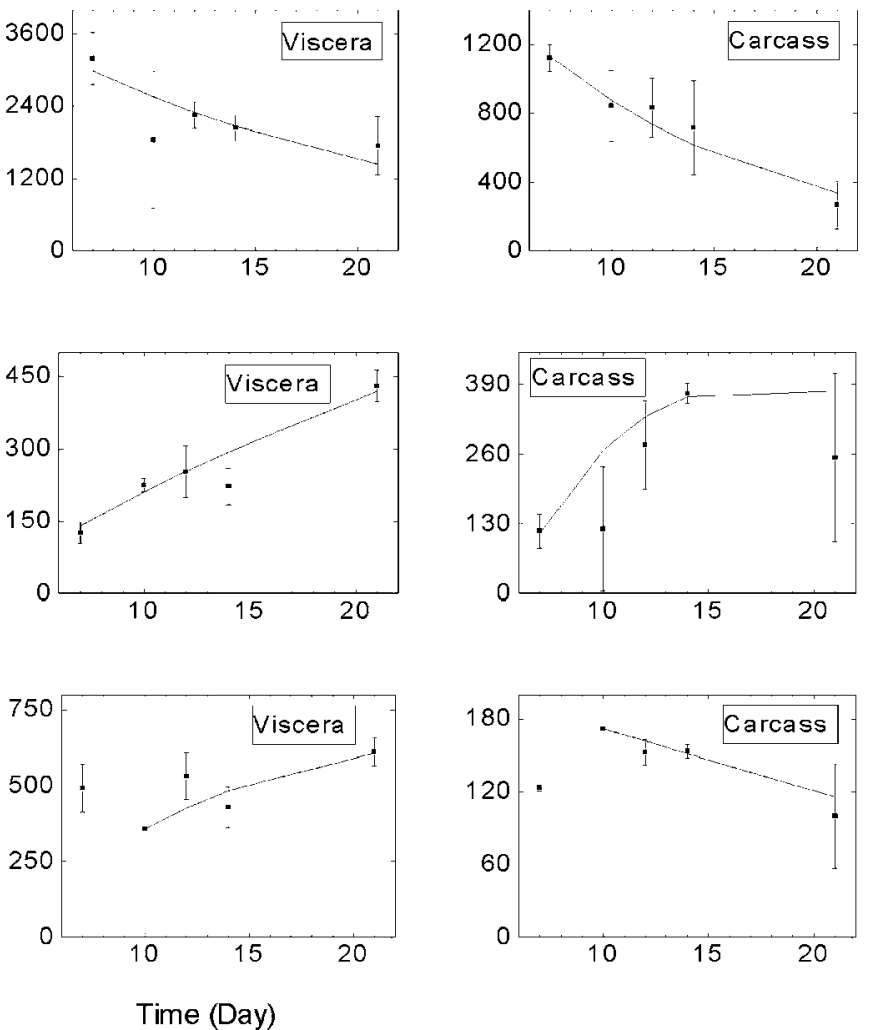

Fig. 7. Concentrations of DDT, $p, p^{\prime}$-dichlorodiphenyldichloroethylene (DDE), and $p, p^{\prime}$-dichlorodiphenyldichloroethane (DDD) in the three compartments of Acanthopagrus schlegeli-(a) gills, (b) viscera, and (c) carcass-following dietary uptake. The line is the best fit, starting from the last day of exposure (day 7-21). Mean \pm standard deviation $(n=3)$.

Some previous studies demonstrated that the main route of DDT exposure was aqueous uptake $[10,22,25]$. In the present study, the fish accumulated DDTs rapidly during the aqueous exposure period, and the concentrations of DDTs in each organ did not reach the steady state by the end of the 7-d exposure period. Apparently, DDT was taken up from the water and distributed among the organs quickly, and allocation from the gills to the viscera was notably more significant than to the carcasses during exposure period. In addition, we observed that the total DDTs in the gills and viscera were significantly higher than the total in the carcasses, which could be attributed to the fact that these organs were the initial sites of exposure, considering that gastrointestine could also be an important route for accumulating pollutants in marine fish [26]. Thus, the high accumulation of DDTs in the viscera could be due to water drinking, at least partly.

Elimination of total DDTs from the fish after aqueous exposure was notably slow, e.g., only $44 \%$ of the total DDTs was eliminated from the whole body after two weeks of depuration. Previous studies also demonstrated that elimination of

Table 4. Summary of the results for dietary uptake of DDT, DDE, and DDD during depuration, including the concentrations at the end of exposure, the removal rates from different subcompartments, and the transfer coefficients from the DDT subcompartment to the DDE and DDD subcompartments ${ }^{\mathrm{ab}}$

\begin{tabular}{lcrr}
\hline & DDT & DDE & DDD \\
\hline Viscera & & & $223 \pm 179$ \\
$q_{V_{0}}(\mathrm{ng} / \mathrm{g})$ & $2,980 \pm 360$ & $141 \pm 33$ & $0.026 \pm 0.135$ \\
$\lambda_{T}, \lambda_{E}$, or $\lambda_{D}\left(\mathrm{~d}^{-1}\right)$ & $0.052 \pm 0.021$ & $-0.013 \pm 0.055$ & $0.019 \pm 0.035$ \\
$f_{E} \lambda_{T}$ or $f_{D} \lambda_{T}\left(\mathrm{~d}^{-1}\right)$ & - & $0.0077 \pm 0.0076$ & $521 \pm 262$ \\
Gills & & & $0.231 \pm 0.825$ \\
$q_{G_{0}}(\mathrm{ng} / \mathrm{g})$ & $2,240 \pm 390$ & $59.1 \pm 18.5$ & $0.020 \pm 0.144$ \\
$\lambda_{T}, \lambda_{E}$, or $\lambda_{D}\left(\mathrm{~d}^{-1}\right)$ & $0.057 \pm 0.026$ & $0.0048 \pm 0.0773$ & \\
$f_{E} \lambda_{T}$ or $f_{D} \lambda_{T}\left(\mathrm{~d}^{-1}\right)$ & - & & \\
Carcass & & $112 \pm 38$ & \\
$q_{T_{0}}(\mathrm{ng} / \mathrm{g})$ & $1,130 \pm 80$ & $0.078 \pm 0.132$ & $0.063 \pm 0.032$ \\
$\lambda_{T}, \lambda_{E}$, or $\lambda_{D}\left(\mathrm{~d}^{-1}\right)$ & $0.086 \pm 0.024$ & $0.068 \pm 0.047$ & $0.0070 \pm 0.050$ \\
$f_{E} \lambda_{T}$ or $f_{D} \lambda_{T}\left(\mathrm{~d}^{-1}\right)$ & - & \\
\hline
\end{tabular}

${ }^{a}$ Mean \pm standard deviation $(n=3)$.

${ }^{\mathrm{b}} \mathrm{DDD}=p, p^{\prime}$-dichlorodiphenyldichloroethane; DDE $=p, p^{\prime}$-dichlorodiphenyldichloroethylene; — = without any values. 
DDT was rather slow and inefficient in marine fish [10]. During depuration, removal of total DDTs from the gills was comparatively faster than from other organs. In addition to blood circulation and DDT reallocation to other organs, the gills were a potential organ for eliminating organic compounds [27], thus contributing to a higher removal rate of DDTs from the gills. On the other hand, the concentrations of DDT metabolites (DDE and DDD) were found to be low over the whole course of the experiment, which might be due to slow DDT metabolism or conversion in fish. However, increase in the ratio of DDE to DDT after long-term depuration could be expected due to its slower elimination rates, especially in the viscera and carcasses.

The major constituent in all organs was DDT, among other compounds (DDE and DDD), although considerable amounts of DDD were also present in the aqueous medium. Therefore, the possibility of preferential or selective accumulation of DDT compounds could not be excluded. In fact, DDD is the least lipophilic compound among all DDT compounds and thus might have a lower bioaccumulation. Concentrations of DDT in the viscera and gills were higher when compared to concentrations in the carcasses, while its retention ability in the viscera was significantly higher than in the gills, with a slow elimination rate. Thus, DDT was absorbed by means of the gills under waterborne exposure, and it was quickly translocated to other parts of the body by means of blood circulation, in which DDT was preferentially retained in the viscera. However, during the depuration period, the proportions of total DDTs in each organ were relatively steady, probably due to the slow biotranslocation process among organs after storage in the fatty tissue.

\section{Dietary uptake}

Trophic transfer is a significant process in the accumulation of DDT by marine fish due to its high dietary assimilation efficiency [10]. Similarly, we demonstrated that the dietborne DDT was rapidly taken up by the fish, whereas accumulation and elimination varied among organs. Elimination of total DDTs from the fish after dietary exposure was slow; only $38 \%$ of the ingested DDTs was eliminated from the whole body after two weeks of depuration, which was comparable to the aqueous exposure (i.e., 44\%). The orders of accumulation among organs following either aqueous or dietary exposure were similar (viscera $>$ gills $>$ carcasses). The viscera not only accumulated the highest amount of DDTs but also had the slowest elimination among other organs (31-34\% over two weeks of depuration). It is interesting to note that the removal rates of DDT in the present study ranged from $0.03 \mathrm{~d}^{-1}$ (aqueous exposure) to $0.06 \mathrm{~d}^{-1}$ (dietary exposure), while Wang and Wang [10] previously reported that the removal rates of DDT for aqueous and dietary exposure in the mangrove snappers were 0.028 and $0.002 \mathrm{~d}^{-1}$, respectively. The higher removal rate constant after dietary exposure in the present study could be attributed to the fact that different species may have different capacities to eliminate contaminants. The food matrix provided in the dietary experiment, as well as the experimental conditions during the depuration phase, may also contribute to such differences. In addition, Wang and Wang [10] used a radiotracer technique in which the radioactivity of total DDTs (DDT, DDD, and DDE) was recorded and no biotransformation was assumed (short-term exposure), whereas substantial biotransformation from DDT to its metabolites following dietary exposure was observed in the present study (discussed later), thereby contributing to the higher clearance of DDT. These findings suggested that the biotransformation process could markedly alter the elimination rates of DDT. Compared to Wang and Wang [10] and our own results, Muir, Hobden, and Servos [28] reported a much lower removal rate constant after aqueous exposure $\left(0.009 \mathrm{~d}^{-1}\right.$ at $\left.10^{\circ} \mathrm{C}\right)$. Apart from the differences in species, the temperature may play an important role in the elimination of organic pollutants in fish [29].

In contrast to aqueous DDT uptake, significantly higher DDT metabolites (DDE and DDD) were observed under dietary DDT exposure, especially in the viscera. This can be explained by the differences in the circulation pathway after absorption. Dietborne DDT was absorbed by the intestine and then transferred to the liver. The liver is known to have high capacity for metabolism and biotransformation; hence, more DDT metabolites would result from dietary exposure. It is interesting to note that the spiked food contained a higher ratio of DDE to DDD, whereas accumulation of DDD in the gills and viscera was always higher than that of DDE, and DDD in the viscera gradually increased over the depuration period. Since the absorption of DDD is expected to be lower than that of DDE due to its lower lipophilicity, the elevated DDD concentrations in the gills and viscera likely originated from the biotransformation process. Our modeling efforts corroborate these observations. Results from the dynamic model revealed that considerable amounts of DDT in the gills and viscera were biotransformed to DDD whereas DDT was biotranformed to DDE in the carcasses after dietborne exposure (discussed later). It is known that DDT can be transformed to DDD through dechlorination and to DDE through dehydrochlorination; however, the biotransformation pathway of DDT and its mechanism in fish is poorly understood. Few potential pathways have been suggested in fish. Malone [30] suggested that the elevated DDD concentrations in the gut of the fish could be attributed to intestinal microflora, which has been shown to play an important role in the dechlorination process of DDT to DDD, thereby increasing DDD body level through dietary exposure of DDT. Kitamura et al. [31] demonstrated that dechlorination of DDT to DDD in fish can occur in the liver and the blood, which is mediated by hemoproteins. These potential pathways may account for the elevated DDD concentrations in the viscera and gills. On the other hand, we observed that concentrations of DDE increased in all organs over the depuration period. The mixed-function oxidase was likely responsible for the dehydrochlorination process of DDT to DDE in fish, which elevated the concentration of DDE in the body of the fish following ingestion and blood circulation [12]. Our findings corroborate with the potential metabolic pathways suggested in fish and further strengthen the conclusion that the biotransformation processes, and thereby the bioaccumulation of each DDT metabolite, vary among organs.

\section{CONCLUSION}

Earlier models, such as partitioning coefficient and bioconcentration factors, have shown to be promising in predicting uptake kinetics of nonionic hydrophobic organic compounds in fish $[13,14]$, and these models are generally used in the risk assessment of environmental contaminants. However, these models are based primarily on the physical-chemical properties of the compound and have limitations in evaluating compounds, which are susceptible to substantial biotransformation. Inaccuracies in predicting the metabolites from these models have been reported $[15,16]$. It is evident that 
biotransformation can play an important role in modifying bioaccumulation, and many studies have demonstrated that biotransformation could significantly affect the fish bioconcentration factor [32,33], as well as the elimination rates of the compounds [34-36]. Therefore, incorporation of biotransformation in ecological risk assessment is essential. In addition, the biokinetics of the metabolites may vary significantly from the primary compound after exposure, which could have important toxicokinetic implications, where each biotransformed product may have different toxicities and biological fates $[18,19]$. In our modeling efforts, for example, we observed that conversion from DDT to DDE may increase the retention time of the toxic compounds in the animals, which may pose a potential adverse consequence. In contrast, conversion from DDT to DDD in fish was likely an additional pathway of facilitating elimination, as the elimination rate of DDD was markedly higher than that of DDT under either aqueous or dietary exposure, especially from the gills. However, few attempts have been made to model and quantify the biotransformation processes of organic compound in fish [37].

In the present study, we employed a dynamic model to quantitatively evaluate the biokinetics of DDTs in fish. The fitted parameters, in particular the transfer coefficients, provide valuable information on the biotransformation from DDT to DDE and DDD in A. schlegeli. To the best of our knowledge, this is the first study to reveal the detailed pathways for bioaccumulation and biotransformation of DDTs in various organs of a fish. From the kinetic models, we observed that during the depuration period a considerable proportion of DDT was biotransformed to DDE or to DDD in the fish under dietary exposure, while the biotransformation capacity and pathway varied among organs. Much DDT was biotransformed to DDE in the carcasses, whereas DDD was likely the major biotransformed product in the viscera and gills. However, we observed that DDD was characterized by a significantly higher elimination rate, whereas no apparent elimination of DDE from the gills and viscera during the depuration period was recorded. Therefore, the high biotransformation from DDT to DDE in the carcasses and the gradual biotransformation from DDT to DDE in the viscera and the gills, together with the high retention ability of DDE, may explain the common observation that fish retain DDE in their bodies from the DDT compounds in the contaminated environment. In our modeling efforts, the variability in the transfer coefficients and the removal rates were quite large for the DDE and DDD subcompartments. The reasons for this are threefold. First, as inferred from Equation 4 , there is interdependency between these two parameters. Second, three parameters have to be fitted from four to five data points during depuration, and these data points are sometimes scattered. Third, there could be high intraspecies variability in the biotransformation and elimination processes [38].

The present study highlights the value of a dynamic model as a reliable tool for quantifying the elimination and biotransformation of DDT and provides valuable insights into the biotransformation pathways in fish. In addition, we demonstrate that the route of exposure significantly affected the fate and biokinetics of DDT in fish, which could have important toxicological implications. Our results indicate that the biotransformation process of DDT in fish was more significant upon dietary exposure than following aqueous uptake and that the process markedly alters the biological fate of DDT in fish. The present modeling efforts also provide the groundwork for a more sophisticated model when more data are available. Future development of the model could incorporate parameters such as growth rate, fecal egestion, and gill elimination. More organ compartments and metabolites, and the possible redistribution of the metabolites, could also be included in the model.

Acknowledgement-The present study was supported by the Areas of Excellence Scheme established under the University Grants Committee of the Hong Kong Special Administrative Region, China (Project AoE/P-04/2004).

\section{REFERENCES}

1. Hargrave BT, Harding GC, Vass WP, Erickson PE, Fowler RB, Scott V. 1992. Organochlorine pesticides and polychlorinated biphenyls in the Arctic Ocean food web. Arch Environ Contom Toxicol 22:41-54.

2. Looser R, Froescheis O, Cailliet GM, Jarman WM, Ballschmiter K. 2000. The deep-sea as a final global sink of semivolatile persistent organic pollutants? II. Organochlorine pesticides in surface and deep-sea dwelling fish of the North and South Atlantic and the Monterey Bay Canyon (California). Chemosphere 40:661670.

3. Zhang G, Parker A, House A, Mai BX, Li XD, Kang YH, Wang ZS. 2002. Sedimentary records of DDT and $\mathrm{HCH}$ in the Pearl River Delta, south China. Environ Sci Technol 36:3671-3677.

4. Qiu X, Zhu T, Yao B, Hu J, Hu S. 2005. Contribution of dicofol to the current DDT pollution in China. Environ Sci Technol 39: 4385-4390.

5. Monirith I, Ueno D, Takahashi S, Nakata H, Sudaryanto A, Subramanian A, Karuppiah S, Ismail A, Muchtar M, Zheng J, Richardson BJ, Prudente M, Hue ND, Tana TS, Tkalin AV, Tanabe S. 2003. Asia-Pacific mussel watch: Monitoring contamination of persistent organochlorine compounds in coastal waters of Asian countries. Mar Pollut Bull 46:281-300.

6. Cheung KC, Leung HM, Kong KY, Wong MH. 2007. Residual level of DDTs and PAHs in freshwater and marine fish from Hong Kong markets and their health risk assessment. Chemosphere 66: 460-468.

7. Meng XZ, Zeng EY, Yu LP, Mai BX, Luo XJ, Ran Y. 2007. Persistent halogenated hydrocarbons in consumer fish of China: Regional and global implications for human exposure. Environ Sci Technol 41:1821-1827.

8. Food and Agriculture Organization of the United Nations. 2003. Overview of fish production, utilization, consumption and trade. Fishery Information, Data and Statistics Unit. Viale delle Terme di Caracalla, Rome, Italy.

9. Kidd KA, Bootsma HA, Hesslein RH, Muir DCG, Hecky RE. 2001. Biomagnification of DDT through the benthic and pelagic food webs of Lake Malawi, East Africa: Importance of trophic level and carbon source. Environ Sci Technol 35:14-20.

10. Wang XH, Wang WX. 2005. Uptake, absorption efficiency and elimination of DDT in marine phytoplankton, copepods and fish. Environ Pollut 136:453-464.

11. Beard J. 2006. DDT and human health. Sci Total Environ 355: 78-89.

12. Murty AS. 1986. Toxicity of Pesticides to Fish, Vols 1 and 2. CRC, Boca Raton, FL, USA.

13. Bertelsen SL, Hoffman AD, Gallinat CA, Elonen CM, Nichols JW. 1998. Evaluation of $\log K_{\mathrm{OW}}$ and tissue lipid content as predictors of chemical partitioning to fish tissues. Environ Toxicol Chem 17:1447-1455.

14. Banerjee S, Baughman GL. 1991. Bioconcentration factors and lipid solubility. Environ Sci Technol 25:536-539.

15. de Wolf W, de Bruijn JHM, Seinen W, Hermens JLM. 1992. Influence of biotransformation on the relationship between bioconcentration factors and octanol-water partition coefficients. Environ Sci Technol 26:1197-1201.

16. Southworth GR, Deffer CC, Beauchamp JJ. 1980. Potential and realized bioconcentration: A comparison of observed and predicted bioconcentration of azaarenes in the fathead minnow ( $P i$ mephales promelas). Environ Sci Technol 14:1529.

17. Lotufo GR, Landrum PF, Gedeon ML, Tigue EA, Herche LR. 2000. Comparative toxicity and toxicokinetics of DDT and its major metabolites in freshwater amphipods. Environ Toxicol Chem 19:368-379.

18. Kwong RWM, Wang WX, Lam PKS, Yu PKN. 2006. The uptake, 
distribution and elimination of paralytic shellfish toxins in mussels and fish exposed to toxic dinoflagellates. Aquat Toxicol 80: 82-91.

19. Yu KN, Kwong RWM, Wang WX, Lam PKS. 2007. Biokinetics of paralytic shellfish toxins in the green-lipped mussel, Perna viridis. Mar Pollut Bull 54:1068-1071.

20. U.S. Environmental Protection Agency. 2000. Method 3620C: Florisil cleanup (revision 3). Test methods for evaluating solid waste, physical/chemical method. SW-846. Technical Report. U.S. Government Printing Office, Washington, DC.

21. Cornish AS, Ng WC, Ho VCM, Wong HL, Lam JCW, Lam PKS, Leung KMY. 2007. Trace metals and organochlorines in the bamboo shark Chiloscyllium plagiosum from the southern waters of Hong Kong, China. Sci Total Environ 376:335-345.

22. Holden AV. 1962. A study of the absorption of ${ }^{14} \mathrm{C}$-labelled DDT from water by fish. Ann Appl Biol 50:467.

23. Premdas FM, Anderson JM. 1963. The uptake and detoxification of ${ }^{14} \mathrm{C}$-labelled DDT in Atlantic salmon, Salmo salar. J Fish Res Board Can 20:827-837.

24. Addison RF, Willis DE. 1978. The metabolism by rainbow trout (Salmo gairderi) of $p, p-\left({ }^{14} \mathrm{C}\right)$ DDT and some of its possible degradation products labeled with ${ }^{14} \mathrm{C}$. Toxicol Appl Pharmacol 43: $303-315$.

25. Jarvinen AW, Hoffman MJ, Thorslund TW. 1977. Long-term toxic effects of DDT food and water exposure on fathead minnows (Pimephales promelas). J Fish Res Board Can 34:2089-2103.

26. Zhang L, Wang WX. 2007. Waterborne cadmium and zinc uptake in a euryhaline teleost Acanthopagrus schlegeli acclimated to different salinities. Aquat Toxicol 84:173-181.

27. McKim JM, Schmieder PK, Erickson RJ. 1986. Toxicokinetic modeling of ${ }^{14} \mathrm{C}$-pentachloro-phenol in the rainbow trout (Salmo gairderi). Aquat Toxicol 9:59-80.

28. Muir DCG, Hobden BR, Servos MR. 1994. Bioconcentration of pyrethroid insecticides and DDT by rainbow trout: Uptake, depuration, and effect of dissolved organic carbon. Aquat Toxicol 29:223-240.
29. Hendriks AJ, van der Linde A, Cornelissen G, Sijm DTHM. 2001 The power of size. I. Rate constants and equilibrium ratios for accumulation of organic substances related to octanol-water partition ratio and species weight. Environ Toxicol Chem 20:14011422.

30. Malone TC. 1970. In vitro conversion of DDT to DDD by the intestinal microflora of the northern anchovy, Engraulis mordax. Nature 227:848-849.

31. Kitamura S, Yoshida M, Sugihara K, Ohta S. 1999. Reductive dechlorination of $p, p^{\prime}$-DDT mediated by hemoproteins in the hepatopancreas and blood of goldfish, Carassius auratus. J Health Sci 45:217-221.

32. Kapoor IP, Metcalf RL, Hirwe AS, Coats JR, Khalsa MS. 1973. Structure activity correlations of biodegradability of DDT analogs. J Agric Food Chem 21:310-315.

33. Werner AF, Kimerle RA. 1982. Uptake and distribution of C12 alkylbenzene in bluegill (Lepomis macrochirus). Environ Toxicol Chem 1:143-146.

34. Lech JJ, Bend JR. 1980. Relationship between biotransformation and the toxicity and fate of xenobiotic chemicals in fish. Environ Health Perspect 34:115-131.

35. Kleinow KM, Melancon MJ, Lech JJ. 1987. Biotransformation and induction: Implications for toxicity, bioaccumulation and monitoring of environmental xenobiotics in fish. Environ Health Perspect 71:105-119.

36. Sijm DTHM, Wever H, Opperhuizen A. 1989. Influence of biotransformation on the accumulation of PCDDs from fly-ash in fish. Chemosphere 19:475-480.

37. van der Linde A, Hendriks AJ, Sijm DTHM. 2001. Estimating biotransformation rate constants of organic chemicals from modeled and measured elimination rates. Chemosphere 44:423-435.

38. Ruus A, Sandvik M, Ugland KI, Skaare JU. 2002. Factors influencing activities of biotransformation enzymes, concentrations and compositional patterns of organochlorine contaminants in members of a marine food web. Aquat Toxicol 61:73-87. 